\title{
Open and Minimally Invasive Technologies in Surgical Treatment of Stable Symptomatic Stenosis of the Lumbar Spine
}

DOI: $10.17691 / \mathrm{stm} 2019.11 .4 .16$

Received August 6, 2019

S.G. Mlyavykh, MD, PhD, Director of the Institute of Traumatology and Orthopedics;

A.E. Bokov, MD, PhD, Head of the Department of Oncology and Neurosurgery, Institute of Traumatology and Orthopedics;

A.Ya. Aleynik, MD, PhD, Neurosurgeon, Institute of Traumatology and Orthopedics;

K.S. Yashin, MD, PhD, Neurosurgeon, Institute of Traumatology and Orthopedics;

N.N. Karyakin, MD, DSc, Rector

Privolzhsky Research Medical University, 10/1 Minin and Pozharsky Square, Nizhny Novgorod, 603005, Russia

The traditional open surgical interventions for symptomatic stenosis (though providing sufficient decompression and stable fixation) have a number of drawbacks. Therefore, today an increasing number of surgeons prefer minimally invasive decompression and fusion. As any new methodology, the process of learning is accompanied with difficulties in assessing the degree of decompression, and also with an increasing risk of intraoperative complications.

The aim of the study was to compare the early and long-term outcomes of the traditional and novel minimally invasive techniques in patients with symptomatic lumbar stenosis without instability of the operated segments, while considering the patient quality of life and satisfaction with the treatment.

Materials and Methods. This ambispective cohort study included 204 patients with symptoms of degenerative stenosis of the lumbar spine; the patients underwent either open (group 1; $n=114$ ) or minimally invasive (group 2; $n=90$ ) surgeries on one or two spinal segments. In group 1, classical laminectomy/interlaminectomy (29.8\%) was performed in combination with posterolateral (5.3\%), transforaminal fusion (60.5\%) or interspinous stabilization (4.4\%). In group 2, we used percutaneous bilateral pedicle osteotomy and lengthening (21.1\%), intralaminar tubular decompression (73.3\%), and transforaminal fusion $(5.6 \%)$.

The minimum postoperative follow-up was 24 months.

Results. In both groups, the limited decompression with foraminotomy prevailed. Minimally invasive procedures were accompanied by a lower intraoperative blood loss and a shorter hospital stay $(p<0.000001)$. There were no statistically significant differences in the incidence of intraoperative complications.

Compared to the preoperative period, the pain syndrome significantly decreased in both groups, and the quality of life improved and remained at the improved level ( $p<0.05$, Wilcoxon's test) throughout the entire observation period.

The long-term results of the treatment (after 2 years) showed no superiority in the open surgery methods. According to the physical health parameters (SF-12), the Oswestry disability index (ODI), and the low back pain score (VAS), the quality of life in patients operated with the minimally invasive technologies was higher $(p<0.03$ ). About 54 and $41 \%$ of patients in group 1 , as well as 67 and $26 \%$ of patients in group 2, were completely and partially (respectively) satisfied with the results of surgical treatment. In group 2, there were a greater number of patients with excellent results (by the MacNab scale), 1 and 2 years after surgery (18.8 vs. $6.1 \%$ and 34.4 vs. $14.9 \%$, respectively). During the first year of observation, unsatisfactory results were more often observed in group 1 ( $p<0.016$ ); after 2 years, the similarly unsatisfactory results developed more often in group 2 ( $p<0.0077)$.

Conclusion. With stable 1-2 levels symptomatic lumbar stenosis, the use of a minimally invasive decompression technology is justified; with unstable stenosis, the minimally invasive spinal fusion can be recommended. Percutaneous osteotomy and lengthening of pedicles, as well as tubular intralaminar micro-decompression, are appropriate alternatives in the presence of mild symptomatic stenosis with/without severe comorbidity.

Key words: degenerative diseases of the spine; symptomatic lumbar stenosis; minimally invasive spinal surgery; quality of life.

Corresponding author: Sergey G. Mlyavykh , e-mail: serg.mlyavykh@gmail.com 


\section{Introduction}

Degenerative stenosis of the lumbar spine is defined as a pathological condition in which, against the background of progressive degenerative changes in the lumbar spinal segments the space available for nerve and vascular elements is reduced. The disease is secondary in nature, its onset and further development is more characteristic of the second half of life, while for the first half, it may exist asymptomatically. From the moment the spectrum of clinical symptoms begins to develop, degenerative lumbar stenosis becomes symptomatic [1]. The symptoms include neurogenic claudication, pain in the lumbosacral region, buttocks and lower extremities, fatigue or a feeling of heaviness in the legs while walking, and neurological deficits of various severities. The prevalence of stenosis in the age group of 60-69 years reaches 20\% (absolute stenosis) and $47 \%$ (relative stenosis) [2], while the frequency of symptomatic lumbar stenosis (SLS) is 10$14 \%[3-5]$.

Numerous clinical trials suggest that the surgical treatment of SLS is superior to the conservative one [6-9]. However, no association was found between the clinical signs of SLS and instrumental diagnostic tests. This situation makes it difficult to propose clear and unambiguous indications for surgery of either type, especially in cases where significant stenosis is detected at several lumbar levels $[10,11]$. On this background, the patient satisfaction with the results of the surgical treatment does not exceed $60-70 \%$ and decreases even more when the patient suffers from axial back pain syndrome [12-14], which is typical of lumbar spine instability.

Today, the choice of surgical treatment should be based on orthopedic (biomechanical) considerations, taking into account the spinal instability and deformity, and syndromic (functional) aspects by focusing on the main syndrome - neurogenic claudication and/ or radicular symptoms and axial pain syndrome [15, 16]. The most favorable outcome of surgical treatment is observed in patients with the predominance of compressed nerve structures in the presence of a morphologically stable lumbar spine. Even in this case, however, there are no clear criteria for choosing the optimal volume of decompression, and such case also requires concomitant rigid or dynamic stabilization.

The commonly used traditional decompression with rigid fixation of the spine, although providing a sufficient volume of decompression, has a number of disadvantages, primarily associated with atrophy and dysfunction of the back muscles, which may cause acute and chronic pain, the development of secondary stenosis and spondylolisthesis, especially in adjacent segments $[17,18]$. Therefore, a number of authors tend to choose various options of minimally invasive (direct or indirect) decompression without using additional rigid fixation, even in the presence of stable spondylolisthesis.
However, in this case, control over the main step of the procedure is complicated, and the risk of later complications and iatrogenic instability in the operated segments increases.

The aim of the study was to compare the early and long-term outcomes of the traditional and novel minimally invasive techniques in patients with symptomatic lumbar stenosis without compromising the stability of the operated segments, while considering the patient quality of life and satisfaction with the treatment.

\section{Materials and Methods}

Patients. This ambispective (retrospective analysis of the prospective database) cohort study included 204 patients with symptoms of degenerative stenosis of the lumbar spine who underwent surgery over a period from January 2009 to December 2016 at the Department of Neurosurgery of the Institute of Traumatology and Orthopedics of the Privolzhsky Research Medical University (Nizhny Novgorod). All operations were performed by three surgeons having over 7 years of experience in spinal surgery.

The criteria for inclusion of patients in the study were (i) age over 40 , (ii) the presence of symptoms of degenerative stenosis ( $\geq 7$ points according to the risk assessment scale for lumbar stenosis of Konno et al. [19]), (iii) the presence of a morphological substrate that compresses the dural sac and/or spinal roots within 1-2 segments (confirmed by MRI and/or CT) for 1 year before surgical treatment, (iv) duration of the disease of at least 6 months and no effectiveness of conservative treatment, and (v) agreement for postoperative observation for at least 2 years and to complete the relevant questionnaires.

The following categories of patients were not included in the study: (i) those with disc extrusion at any level of the lumbar spine, (ii) patients with clear signs of instability of lumbar segments according to White-Panjabi [20], (iii) patients with severe structural deformations of the lumbar spine (spondylolysis-caused spondylolisthesis, angle of scoliotic deformation $>20^{\circ}$ according to Cobb [21], apical rotation of $\geq 2^{\text {nd }}$ grade according to NashMoe, and a deviation of global sagittal balance), (iv) any previous surgical interventions on the lumbar spine, and (v) patients with newly detected or previously diagnosed tumors, fractures, infectious spondylitis (spondylodiscitis), regardless of their location.

The study was conducted in accordance with the Helsinki Declaration (2013) and approved by the Ethics Committee of the Privolzhsky Research Medical University. Informed consent was obtained from each patient.

Two groups of patients were formed considering the technique of surgical intervention: group 1 $(n=114)$ - patients operated using the "open" posterior approach; group 2 ( $n=90)$ - patients who underwent decompression or decompression-fusion operations 
Table 1

General characteristics of patients in the open and minimally invasive surgical procedures groups (Me [Q1; Q3])

\begin{tabular}{lccc}
\hline \multicolumn{1}{c}{ Parameters } & $\begin{array}{c}\text { Group } 1(\mathrm{n}=114), \\
\text { open technologies }\end{array}$ & $\begin{array}{c}\text { Group 2 }(\mathrm{n}=90), \\
\text { minimally invasive } \\
\text { technologies }\end{array}$ & p \\
\hline Sex (m/f) & $54 / 60$ & $34 / 56$ & $0.21^{1}$ \\
\hline Age (years) & $61[55 ; 65]$ & $62[54 ; 68]$ & $0.8^{2}$ \\
\hline BMl: $<20 / 20-26 / 27-30 / 31-35 />35$ & $0 / 22 / 58 / 23 / 11$ & $0 / 19 / 36 / 28 / 7$ & $0.26^{3}$ \\
\hline Charlson index of comorbidity: 0/1/2/3/4/5/6 (scores) & $57 / 4 / 12 / 22 / 12 / 5 / 2$ & $47 / 3 / 12 / 17 / 7 / 4 / 0$ & $0.88^{3}$ \\
\hline ASA classification: $1 / 2 / 3 / 4$ (scores) & $1 / 21 / 92 / 0$ & $3 / 18 / 68 / 1$ & $0.38^{3}$ \\
\hline Duration of conservative treatment before surgery: & & & \\
$<12$ months/>12 months & $36 / 78$ & $23 / 67$ & $0.43^{1}$ \\
\hline Stenosis spread over: 1 segment/2 segments & $70 / 44$ & $68 / 22$ & $0.08^{1}$ \\
\hline Category of stenosis by MRI data [21]: B/C/D & $3 / 65 / 46$ & $6 / 54 / 30$ & $0.27^{3}$ \\
\hline
\end{tabular}

$\mathrm{N}$ o t e: ${ }^{1}-\chi^{2}$ criterion with Yates correction; ${ }^{2}-$ Mann-Whitney U-test; ${ }^{3}-\chi^{2}$ Pearson criterion.

with minimally invasive technologies. The groups did not significantly differ by sex, age, body mass index, comorbidity, the duration of conservative treatment before the surgery, or the extent and severity of stenosis according to MRI (Table 1).

Surgical technique. In patients of both groups, operations were performed using posterior approach to the spine under general anesthesia; in 138 patients $(67.6 \%)$, one segment was involved and in 66 patients $(32.4 \%)$ - two segments. In the open surgery group, classical laminectomy or interlaminectomy (29.8\%) was used in combination with posterolateral $(5.3 \%)$, transforaminal spinal fusion $(60.5 \%)$ and rigid pedicle fixation or in combination with interspinous stabilization $(4.4 \%)$. The surgery techniques used in this group did not differ from generally accepted ones.

In the group of minimally invasive operations, percutaneous bilateral transpedicle osteotomy and lengthening of the pedicles $(21.1 \%)$ or intra-laminar bilateral decompression with the monolateral tubular approach $(73.3 \%)$ were performed, including in combination with transforaminal fusion $(5.6 \%)$.

Percutaneous osteotomy and vertebral pedicle lengthening. The procedure was performed according to the original technique developed earlier [22]. After a $10 \mathrm{~mm}$ puncture of the skin, subcutaneous tissue and fascia, a canal is formed in the pedicle of a vertebra under fluoro control. Using a radial bone saw installed in the canal, osteotomy of the pedicle is performed in the area of its connection to the vertebral body. For the sake of safety, the surgeon verifies every step of the procedure by the tactile sensations and the fluoroscopy. After the osteotomy is completed, implants are inserted into the canals of the vertebral pedicles (the implant is shaped as an expandable three-component pedicle screw). Using special screwdrivers, the threaded mechanisms of the internal components of the implants are simultaneously actuated; the implants get elongated, thus increasing the bone defects in the areas of osteotomy. As a result, the vertebral pedicles also become elongated, and the spinal canal and foraminal openings expand (Figure 1). Before completing the procedure, the surgeon blocks the installed implants in such a way that the pedicles are stabilized in an elongated position until they fuse.

Intralaminar unilateral or bilateral microdecompression by the monolateral minimally invasive approach. The procedure was performed using an original set [23] of olive non-expandable tubular retractors (Figure 2). In the cases where only decompression was required, a small oval tubular retractor was used. If interbody fusion was required to complete the operation, a medium olive tubular retractor was added. After installing the retractor and completing the fluoro control, all manipulations were performed using a microscope.

At the first stage, the distal and lateral edges of the vertebral arch are identified. Using high-speed burs, arch-shaped laminotomy is performed on the side of the installed tube from the medial edge of the articular process through the base of the spinous process to the midline, and in the cranial direction to the border of the ligamentum flavum attachment. Then the ligamentum flavum is separated from the arc, and the tube is rotated $90^{\circ}$ along its axis; after that, the base of the spinous process of the overlying vertebra is resected to visualize the contralateral part of the arc.

For the convenience of performing the subsequent steps, the operating table and tube are tilted in the direction of the contralateral side. The ligamentum flavum is separated from the edge of the contralateral part of the arches of the upper and lower vertebrae and 

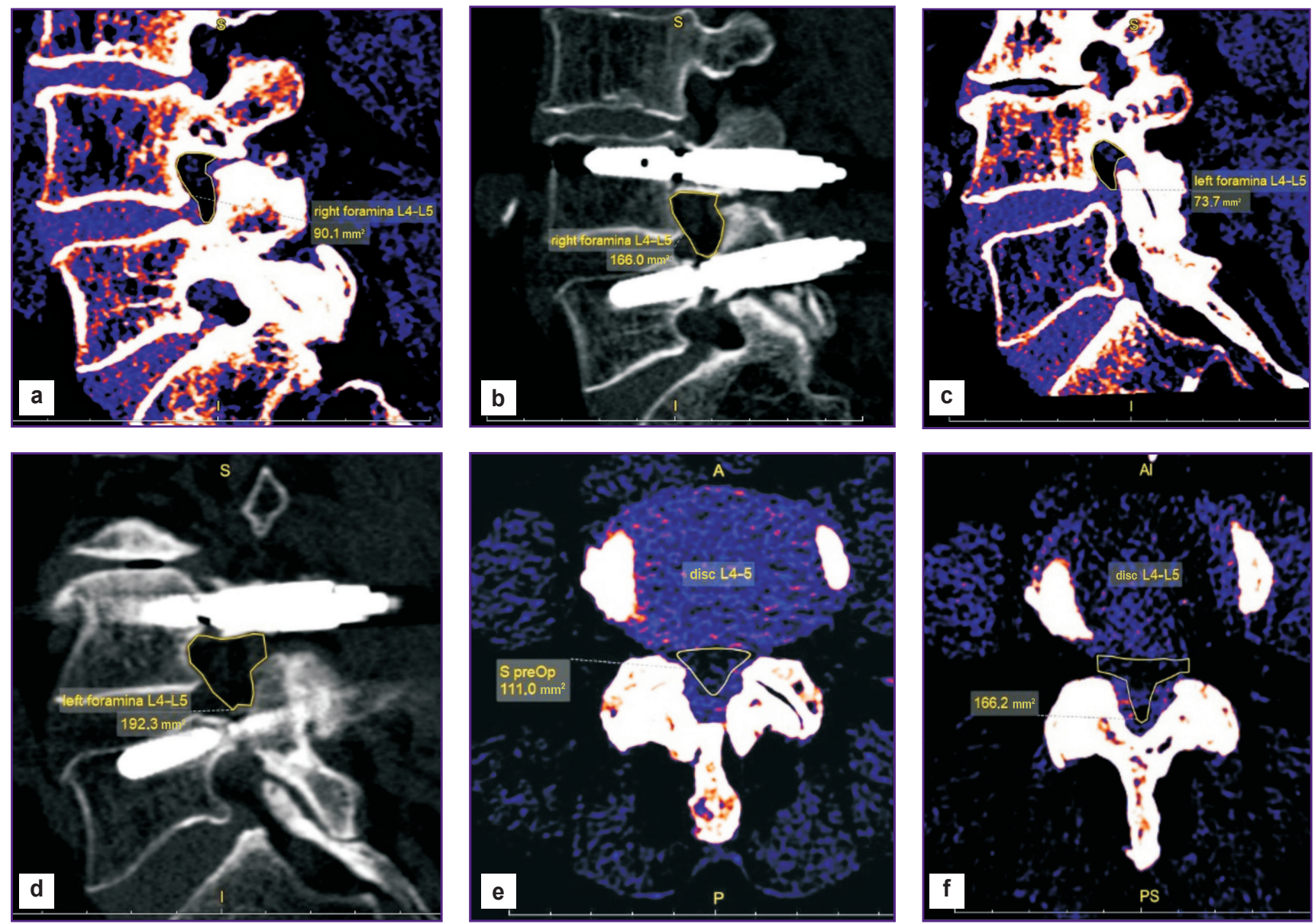

Figure 1. Computed tomography in patient S., 74 years old, operated for stable lumbar stenosis using osteotomy and pedicle lengthening in the $L_{4}$ and $L_{5}$ vertebrae:

sagittal scans at the level of the $\mathrm{L}_{4-5}$ foraminal openings on the right before (a) and after (b) the operation and on the left before (c) and after (d) the operation; axial scans at the level of the $L_{4-5}$ intervertebral disc before (e) and after (f) the operation; the yellow line denotes the boundaries of the foramens and the spinal canal; the cross-sectional areas computed in $\mathrm{mm}^{2}$ are also shown

is resected; then, the released edges of the arcs are resected using a diamond bur.

The next step - medial facetectomy and foraminotomy of the contralateral side - is performed using Kerrison rongeur; while gradually moving in the opposite direction, the ligamentum flavum (previously separated from the arches) is removed. After that, the operating table and the tube are returned to their original positions. Then the final resection of the upper edge of the underlying vertebra on the ipsilateral side and the removal of ligamentum flavum remnants followed by medial facetectomy and foraminotomy on the ipsilateral side are performed. Before the foraminotomy, the tube is again turned by $45^{\circ}$ along its axis to help manipulate with the curved Kerrison rongeur and a surgical retractor.

After the decompression is completed, the surgical wound is checked for epidural bleeding and then washed with saline. The retractor is gradually removed from the operation field and the concluding hemostasis of the soft tissues is established. A suture is applied to the fascia and the skin. In order to reduce postoperative pain, the muscle layer surrounding the facet joint on the operated side is applicated with local anesthetic of a specified concentration in a volume not exceeding $20 \mathrm{ml}$.

Evaluation of treatment outcomes. To objectify and standardize the clinical manifestations of SLS, standard scales and questionnaires were utilized: the $100 \mathrm{~mm}$ visual analogue pain scale (VAS), the Oswestry Disability Index (ODI, version 2.0) [24], the Zurich Claudication Questionnaire (ZCQ) for assessing the quality of life in patients with intermittent claudication [12, 25], a concise version of the quality of life questionnaire (SF-12, version 2) with the indices of physical and mental components of health [26]. Quality of life was assessed two weeks before surgery and 1 and 2 years after that. According to the results obtained with the ZCQ, ODI, and SF-12 scores, no significant differences were found between the compared groups. Compression syndrome was clinically predominant in both groups, but in the group of minimally invasive technologies, it was significantly more intense (Table 2).

A comprehensive assessment of treatment results 

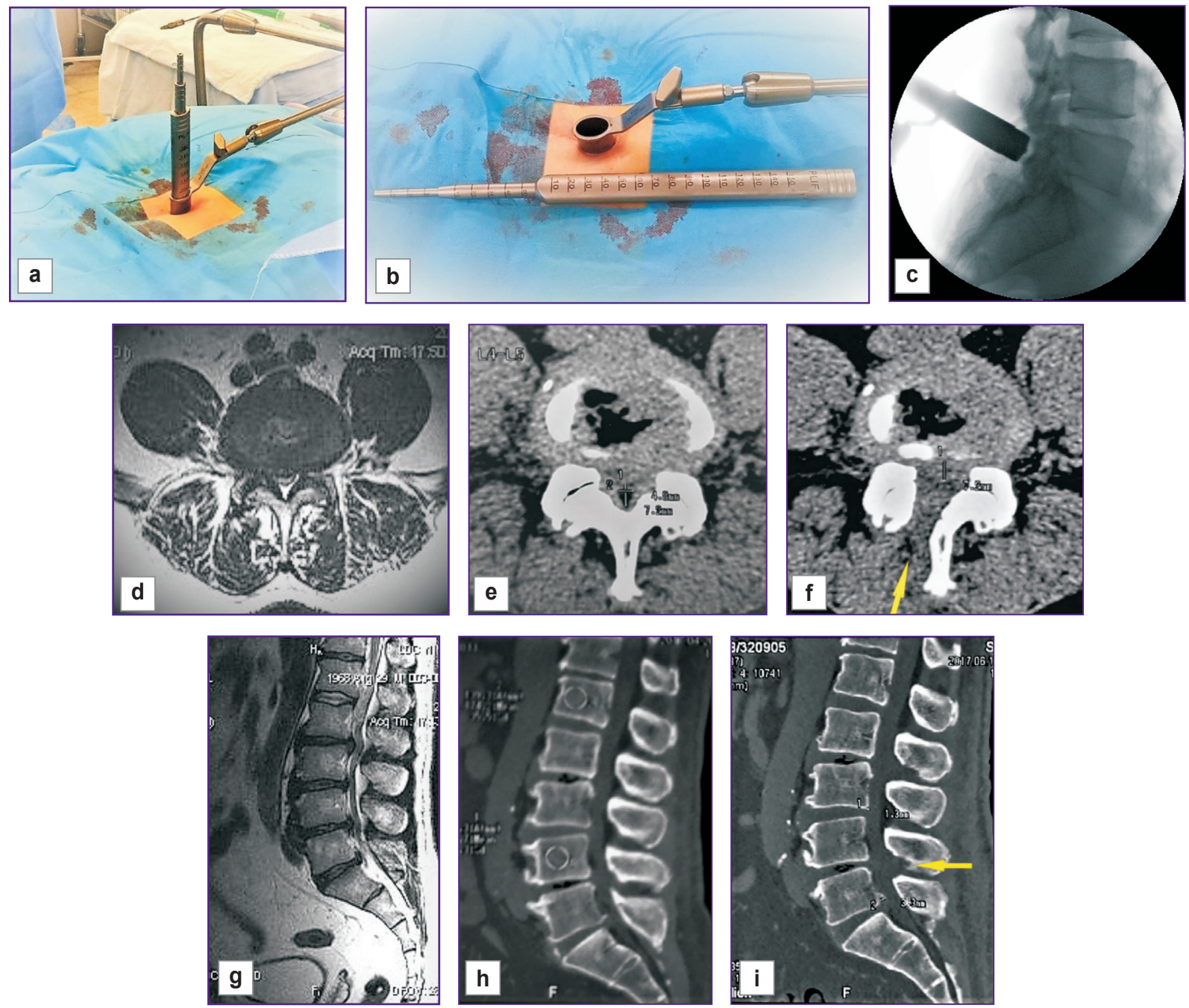

Figure 2. Patient S., 59 years old, operated for stable lumbar stenosis using bilateral tubular microsurgical decompression at the $\mathrm{L}_{4-5}$ level:

the olive tubular retractor located in the wound: general view before (a) and after (b) the removal of muscle expanders; intraoperative fluoro images (c); axial (d)-(f) and sagittal (g)-(i) scans: MRI before (d), (g), CT before (e), (h) and CT after (f), (i) minimally invasive decompression. The yellow arrows indicate the defect in the vertebral arch formed during decompression

Table 2

Assessment of the patients before surgery in the open and minimally invasive groups using questionnaires (Me [Q1; Q3])

\begin{tabular}{lccc}
\hline \multicolumn{1}{c}{ Parameters } & $\begin{array}{c}\text { Group 1 }(\mathrm{n}=114), \\
\text { open technologies }\end{array}$ & $\begin{array}{c}\text { Group 2 }(\mathrm{n}=90), \\
\text { minimally invasive } \\
\text { technologies }\end{array}$ & $\begin{array}{c}\text { p, } \\
\text { Mann-Whitney }\end{array}$ \\
\hline VAS, back pain (mm) & $51[30 ; 70]$ & $38.5[20 ; 60]$ & $\mathbf{0 . 0 0 5 9}$ \\
VAS, leg pain (mm) & $61.5[40 ; 72]$ & $72[52 ; 86]$ & $\mathbf{0 . 0 0 0 2 2}$ \\
\hline Oswestry scale, ODI (\%) & $52[44 ; 62]$ & $54[44 ; 60]$ & 0.82 \\
\hline SF-12 physical component score & $30.3[25.9 ; 35.3]$ & $30.1[24.3 ; 34.3]$ & 0.27 \\
\hline SF-12 psychological component score & $37.7[32.1 ; 40.7]$ & $37.7[32.9 ; 41.1]$ & 0.84 \\
\hline ZCQ (SS1-SS7 - symptom manifestation) score & $3.1[2.7 ; 3.5]$ & $3.2[2.7 ; 3.7]$ & 0.28 \\
\hline ZCQ (SS8-SS12 - physical activity) score & $2.8[2.2 ; 3.4]$ & $2.6[2.1 ; 3.2]$ & 0.42 \\
\hline ZCQ (SS1-SS12 - validity) score & $3.0[2.5 ; 3.2]$ & $2.9[2.5 ; 3.3]$ & 0.82 \\
\hline
\end{tabular}


after 1 and 2 years of postoperative observation was carried out using the modified MacNab scale [27].

Statistical processing of material. The data comparison between the groups following pre- and post-operative examinations was carried out using the Statistica 10.0 software package. Comparison between the treatment results was performed using nonparametric statistical methods.

\section{Results}

Surgical treatment of patients. The indicators of surgical treatment in patients of both groups are presented in Table 3. In both groups, the sparing

Table 3

Characteristics of the open and minimally invasive procedures (Me [Q1; Q3])

\begin{tabular}{lccc}
\hline \multicolumn{1}{c}{ Parameters } & $\begin{array}{c}\text { Group } 1(\mathrm{n}=114), \\
\text { open technologies }\end{array}$ & $\begin{array}{c}\text { Group 2 }(\mathrm{n}=90), \\
\text { minimally invasive } \\
\text { technologies }\end{array}$ & \multicolumn{1}{c}{$\mathbf{p}$} \\
\hline $\begin{array}{l}\text { Decompression volume: } n \text { nolimited/limited } \\
\text { with foraminotomy/expanded/total }\end{array}$ & $2 / 20 / 51 / 39 / 2$ & $22 / 19 / 48 / 1 / 0$ & $<0.000001^{1}$ \\
$\begin{array}{l}\text { Blood loss: }<100 / 100-500 / 500-1000 / \\
>1000 \mathrm{ml}\end{array}$ & $21 / 86 / 5 / 2$ & $81 / 9 / 0 / 0$ & $<0.000001^{1}$ \\
\hline Time of surgery (min) & $155[130 ; 170]$ & $100[80 ; 115]$ & $<0.000001^{2}$ \\
$\begin{array}{l}\text { Intraoperative complication: damage } \\
\text { of dura mater/root/no }\end{array}$ & $1 / 7 / 106$ & $0 / 2 / 88$ & $0.26^{1}$ \\
\hline Hospital stay after surgery (days) & $8[7 ; 10]$ & $3[3 ; 4]$ & $<0.000001^{2}$ \\
\hline
\end{tabular}

N o t e: ${ }^{1}-\chi^{2}$ Pearson criterion; ${ }^{2}-$ Mann-Whitney U-test.

Table 4

Two-year clinical outcomes after surgery in the minimally invasive and open surgical groups using questionnaires (Me [Q1; Q3])

\begin{tabular}{|c|c|c|c|}
\hline Parameters & $\begin{array}{l}\text { Group } 1 \\
\text { (n=114), open } \\
\text { technologies }\end{array}$ & $\begin{array}{l}\text { Group } 2(n=90) \\
\text { minimally invasive } \\
\text { technologies }\end{array}$ & $p$ \\
\hline VAS, back pain (mm) & 37 [24; 45] & $26[20 ; 37]$ & $0.00035^{1}$ \\
\hline VAS, leg pain (mm) & $18.5[10 ; 30]$ & $17.5[10 ; 30]$ & $0.73^{1}$ \\
\hline Oswestry scale, ODI (\%) & $42[30 ; 48]$ & 38 [26; 44] & 0.03 \\
\hline SF-12 physical component score & $37.5[33.5 ; 40.3]$ & $37.6[32.9 ; 46.2]$ & $0.38^{1}$ \\
\hline SF-12 psychological component score & $42.5[38.4 ; 44.9]$ & $44.2[39.9 ; 48.9]$ & $0.013^{1}$ \\
\hline ZCQ (SS1-SS7 - symptom manifestation) score & $2.3[1.8 ; 3.0]$ & $2.1[1.8 ; 2.5]$ & $0.13^{1}$ \\
\hline ZCQ (SS8-SS12 - physical activity) score & $1.8[1.4 ; 2.4]$ & $1.8[1.4 ; 2.4]$ & $0.66^{1}$ \\
\hline ZCQ (SS1-SS12 - validity) score & $2.2[1.7 ; 2.6]$ & $2.0[1.7 ; 2.4]$ & $0.21^{1}$ \\
\hline $\begin{array}{l}\text { ZCQ (SS13-SS18 - satisfaction } \\
\text { with the treatment results) score }\end{array}$ & $1.8[1.4 ; 2.4]$ & $1.6[1.3 ; 2.0]$ & $0.18^{1}$ \\
\hline $\begin{array}{l}\text { Satisfaction with the treatment results } \\
\text { after } 2 \text { years, according to ZCQ: completely } \\
\text { satisfied/partially satisfied/completely dissatisfied }\end{array}$ & $61 / 47 / 6$ & $60 / 23 / 7$ & $0.06^{2}$ \\
\hline MacNab scale: & & & \\
\hline $\begin{array}{l}1^{\text {st }} \text { year: } 1 / 2 / 3 / 4 \text { grade } \\
2^{\text {nd }} \text { year: } 1 / 2 / 3 / 4 \text { grade }\end{array}$ & $\begin{array}{l}7 / 59 / 38 / 10 \\
17 / 56 / 37 / 4\end{array}$ & $\begin{array}{l}17 / 38 / 32 / 3 \\
31 / 32 / 22 / 5\end{array}$ & $\begin{array}{l}0.016^{2} \\
0.0077^{2}\end{array}$ \\
\hline
\end{tabular}

N o t e : ${ }^{1}-$ Mann-Whitney U-test; ${ }^{2}-\chi^{2}$ Pearson criterion. technique of decompression with foraminotomy was used in most cases. At the same time, in the group of traditional procedures, extended and total decompression options were performed more often, whereas in the group of minimally invasive approach, sparing and indirect decompression prevailed. In group 2, we observed a lower volume of intraoperative bleeding, a shorter duration of surgery, and a shorter postoperative stay in the hospital $(p<0.05)$. There were no statistically significant differences in the incidence of intraoperative complications.

Comparative analysis of clinical results. In both groups, there was a statistically significant improvement in patients' condition according to the VAS scale and the ODI, ZCQ, SF-12 questionnaires throughout the entire period of postoperative observation $(p<0.05$, Wilcoxon test).

Analysis of the long-term (at least 24 months after surgery) results based on the ODI, ZCQ, VAS, and SF-12 scales showed no advantages in the group of open intervention. Moreover, according to the physical assessment (SF-12 questionnaires), the disability index (ODI), the level of back pain (VAS), and the quality of life in patients who underwent minimally invasive surgery were significantly better. Almost $54 \%$ of patients after open surgery and $67 \%$ of patients after minimally invasive procedures were completely satisfied with the results of surgical treatment, and 41 and 26\% (respectively) expressed partial satisfaction at the end of the two-year postoperative observation.

An analysis of long-term outcomes by the modified MacNab scale revealed that the number of patients with "excellent" results was higher in the group of minimally invasive procedures: after the $1^{\text {st }}$ year, 18.8 vs. $6.1 \%$ (group 1 and group 2, respectively) and after the $2^{\text {nd }}$ year, 34.4 vs. $14.9 \%$ (group 1 and group 2). The unsatisfactory results that required a later revision were more frequent in the open intervention group (8.7 vs. $3.3 \%$ ) during the first year of observation; however, by the 
end of the second year, the trend had changed so that unfavorable outcomes were noted more often in the minimally invasive group (5.5 vs. $3.5 \%$ ) (Table 4).

\section{Discussion}

The increase in life expectancy and the associated increase in SLS prevalence, together with its impact on the quality of life and the increasing costs of treatment for patients with SLS - all these factors necessitate a revision of existing recommendations for the treatment. The path to achieving this goal is not easy because of the variety of non-correlating clinical forms of SLS and data of instrumental assessment diagnostics, as well as a large number of mixed etiological factors, (e.g., extravertebral pathology) to be taken into account. Nevertheless, at present, surgical treatment of SLS is apparently the most effective method and considered to be the gold standard. Thus, according to the Swedish National Register, the average annual level of surgical interventions for SLS increased from 10-15 per 100,000 population in 2003 to $30-35$ in 2013 [14, 28].

Despite the commonly accepted superiority of surgery over conservative treatment, numerous clinical trials [6] failed to result in consistent conclusions about the preferable type of surgical intervention; there is no consensus either on what treatments should be used in various forms of stenosis $[29,30]$. In this regard, the efficacy of minimally invasive approach and spinal fusion for SLS continue to be extensively discussed in the literature [31-33].

The open fusion proponents argue that for SLS, especially when combined with degenerative spondylolisthesis, this open surgery is more technically attainable as it results in a back pain relief by stabilizing the degenerated segment, and also prevents the progression of mechanical instability, including the one resulting from surgical decompression, thereby minimizing the risk of residual pain or new neurological symptoms [31, 33, 34].

The arguments for minimally invasive decompression are that in the absence of spondylolisthesis or with its stable nature, the results of open and minimally invasive operations are, by large, identical [35]. Moreover, open spinal fusion significantly increases the cost of the treatment and represents a proven risk factor for the development of complications and progressive degeneration of adjacent segments [36-39]. After the operation, about a half of the patients remain unsatisfied with its results; after $4-5$ years, the quality of life of the operated and non-operated patients becomes similar in many aspects [12-14].

The aim of the present study was to retrospectively analyze the long-term clinical results of surgical treatment of degenerative stenosis of the lumbar spine using either open and or minimally invasive technologies, including those developed by the authors. All patients included in the final cohort showed no signs of instability, gross disturbance of sagittal/ frontal balance, or degenerative scoliosis. At the same time, some of the operated patients had ante- or retrospondylolisthesis, accompanied by severe hypertrophy of the facet joints and secondary circular narrowing of the spinal canal and/or foraminal openings. Since the X-ray morphometric parameters in SLS have no clear standardization and often do not correlate with the symptoms, we, like many others, mainly focused on clinical results, namely, the pain syndrome, quality of life and patient satisfaction with the treatment using the commonly accepted scales and questionnaires [40-42].

A comparative assessment of the short- and longterm (2 years) postoperative outcomes demonstrated a significant advantage of the minimally invasive approach, including the technologies developed and modified by our group. The clinical importance of the minimally invasive treatment is especially relevant for elderly patients.

Therefore, in the absence of convincing data on the superiority of open surgery in patients with one-twolevel stable lumbar stenosis, we recommend using the minimally invasive procedure, which is primarily aimed at eliminating the clinical manifestations of the compression syndrome and maintaining the stability of affected segments. Moreover, in stage 3 of the degenerative process (restabilization), there is no need for a complete correction of anatomical defects, in particular anterolisthesis or retrolisthesis. Our point of view is at odds with the common opinion that the surgeon must correct any deformity in the hope of eliminating a subsequent instability. This theory of the so-called preventive approach to surgical treatment of degenerative stenosis of the lumbar spine is not fully justified, but the risk of serious complications, the duration of rehabilitation and the economic costs of open reconstructive surgery increase significantly.

The main limitation of the study is its retrospective nature and insufficient sample size. Additional difficulties arise in older patient during the long period of observation due to the progression of concomitant impairments and the lack of information on psychosocial and emotional factors, which, as reported in the literature, could have a significant impact on the quality of life and the patient self-assessment about their disease caused by a degenerative process in the spine [12, 26-28]. In addition, even a significant experience of one medical center may not be applicable to the general situation with surgical treatment of SLS, as its staffing and technical capabilities do not reflect the situations in other specialized medical institutions, and some of the technologies have not yet become part of the arsenal of surgeons.

\section{Conclusion}

Based on the presented data, we believe that in patients with proven clinical and morphological 
manifestations of stable lumbar stenosis within 1-2 segments, the use of one of the minimally invasive decompression technologies is pathogenetically substantiated. In this approach, such stabilizing structures as facet joints and interspinous ligaments remain intact in many cases. When it is impossible to save them, the surgeon can successfully apply the technology of minimally invasive spinal fusion. Percutaneous osteotomy and vertebral pedicle lengthening as well as tubular intralaminar micro-decompression, are viable surgical treatments for patients with moderate symptoms and/or severe comorbidity.

Study funding. The study was not funded by any sources.

Conflict of interest. The authors declare no conflicts of interest.

\section{References}

1. Suri P., Rainville J., Kalichman L., Katz J.N. Does this older adult with lower extremity pain have the clinical syndrome of lumbar spinal stenosis? Jama 2010; 304(23): 2628-2636, https://doi.org/10.1001/jama.2010.1833.

2. Kalichman L., Cole R., Kim D.H., Li L., Suri P., Guermazi A., Hunter D.J. Spinal stenosis prevalence and association with symptoms: the Framingham Study. Spine J 2009; 9(7): 545-550, https://doi.org/10.1016/j. spinee.2009.03.005.

3. Ammendolia C., Stuber K.J., Rok E., Rampersaud R., Kennedy C.A., Pennick V., Steenstra I.A., de Bruin L.K., Furlan A.D. Nonoperative treatment for lumbar spinal stenosis with neurogenic claudication. Cochrane Database Syst Rev 2013, https://doi.org/10.1002/14651858.cd010712.

4. Katz J.N., Harris M.B. Lumbar spinal stenosis. N Engl J Med 2008; 358(8): 818-825, https://doi.org/10.1056/ nejmcp0708097.

5. Ishimoto Y., Yoshimura N., Muraki S., Yamada H., Nagata K., Hashizume H., Takiguchi N., Minamide A., Oka H., Kawaguchi H., Nakamura K., Akune T., Yoshida M. Prevalence of symptomatic lumbar spinal stenosis and its association with physical performance in a population-based cohort in Japan: the Wakayama Spine Study. Osteoarthritis Cartilage 2012; 20(10): 1103-1108, https://doi.org/10.1016/j. joca.2012.06.018.

6. Malmivaara A., Slätis P., Heliövaara M., Sainio P., Kinnunen H., Kankare J., Dalin-Hirvonen N., Seitsalo S., Herno A., Kortekangas P., Niinimäki T., Rönty H., Tallroth K., Turunen V., Knekt P., Härkänen T., Hurri H.; Finnish Lumbar Spinal Research Group. Surgical or nonoperative treatment for lumbar spinal stenosis? A randomized controlled trial. Spine 2007; 32(1): 1-8, https://doi.org/10.1097/01. brs.0000251014.81875.6d.

7. Weinstein J.N., Tosteson T.D., Lurie J.D., Tosteson A.N., Blood E., Hanscom B., Herkowitz H., Cammisa F., Albert T., Boden S.D., Hilibrand A., Goldberg H., Berven S., An H.; SPORT Investigators. Surgical versus nonsurgical therapy for lumbar spinal stenosis. N Engl J Med 2008; 358(8): 794-810, https://doi.org/10.1056/nejmoa0707136.

8. Lurie J.D., Tosteson A.N., Tosteson T.D., Carragee E., Carrino J.A., Kaiser J., Sequeiros R.T., Lecomte A.R.,
Grove M.R., Blood E.A., Pearson L.H., Weinstein J.N., Herzog R. Reliability of readings of magnetic resonance imaging features of lumbar spinal stenosis. Spine 2008; 33(14): 1605-1610, https://doi.org/10.1097/brs.0b013e3181791af3.

9. Lurie J.D., Tosteson T.D., Tosteson A., Abdu W.A., Zhao W., Morgan T.S., Weinstein J.N. Long-term outcomes of lumbar spinal stenosis. Spine 2015; 40(2): 63-76, https://doi. org/10.1097/brs.0000000000000731.

10. Boden S.D., Davis D.O., Dina T.S., Patronas N.J., Wiesel S.W. Abnormal magnetic-resonance scans of the lumbar spine in asymptomatic subjects. A prospective investigation. J Bone Joint Surg Am 1990; 72(3): 403-408, https://doi.org/10.2106/00004623-199072030-00013.

11. Boden S.D., McCowin P., Davis D., Dina T., Mark A., Wiesel S. Abnormal magnetic-resonance scans of the cervical spine in asymptomatic subjects. A prospective investigation. J Bone Joint Surg Am 1990; 72(8): 1178-1184, https://doi. org/10.2106/00004623-199072080-00008.

12. Stucki G., Liang M.H., Fossel A.H., Katz J.N. Relative responsiveness of condition-specific and generic health status measures in degenerative lumbar spinal stenosis. J Clin Epidemiol 1995; 48(11): 1369-1378, https://doi. org/10.1016/0895-4356(95)00054-2.

13. Weinstein J.N., Tosteson T.D., Lurie J.D., Tosteson A., Blood E., Herkowitz H., Cammisa F., Albert T., Boden S.D., Hilibrand A., Goldberg H., Berven S., An H. Surgical versus nonoperative treatment for lumbar spinal stenosis fouryear results of the spine patient outcomes research trial. Spine 2010; 35(14): 1329-1338, https://doi.org/10.1097/ brs.0b013e3181e0f04d.

14. Strömqvist B., Fritzell P., Hägg O., Jönsson B., Sandén B.; Swedish Society of Spinal Surgeons. Swespine: the Swedish spine register: the 2012 report. Eur Spine J 2013; 22(4): 953-974, https://doi.org/10.1007/s00586-013-2758-9.

15. Lee J.Y., Whang P.G., Lee J.Y., Phillips F.M., Patel A.A. Lumbar spinal stenosis. Instr Course Lect 2013; 62: 383-396.

16. Goh K.J., Khalifa W., Anslow P., Cadoux-Hudson T., Donaghy $M$. The clinical syndrome associated with lumbar spinal stenosis. Eur Neurol 2004; 52(4): 242-249, https://doi. org/10.1159/000082369.

17. Cawley D.T., Alexander M., Morris S. Multifidus innervation and muscle assessment post-spinal surgery. Eur Spine J 2013; 23(2): 320-327, https://doi.org/10.1007/s00586013-2962-7.

18. Keller A., Brox J.I., Gunderson R., Holm I., Friis A., Reikeras O. Trunk muscle strength, cross-sectional area, and density in patients with chronic low back pain randomized to lumbar fusion or cognitive intervention and exercises. Spine 2004; 29(1): 3-8, https://doi.org/10.1097/01. brs.0000103946.26548.eb.

19. Konno S., Hayashino Y., Fukuhara S., Kikuchi S., Kaneda K., Seichi A., Chiba K., Satomi K., Nagata K., Kawai S. Development of a clinical diagnosis support tool to identify patients with lumbar spinal stenosis. Eur Spine J 2007; 16(11): 1951-1957, https://doi.org/10.1007/s00586-007-0402-2.

20. White A.A., Panjabi M.M. Clinical biomechanics of the spine. Philadelphia: JB Lippincott; 1990.

21. Schizas C., Theumann N., Burn A., Tansey R., Wardlaw D., Smith F.W., Kulik G. Qualitative grading of severity of lumbar spinal stenosis based on the morphology of the dural sac on magnetic resonance images. Spine 2010; 35(21): 1919-1924, https://doi.org/10.1097/brs.0b013e3181d359bd.

22. Mlyavykh S.G., Anderson D.G. Method of surgical 
treatment of spinal stenosis of lumbar spine and device for its realization. Patent RU 2462203. 2012.

23. Mlyavykh S.G., Bokov A.E., Alejnik A.Ya. An access technique to different spinal structures, and a device to bring it into action. Application for a patent RU 2019126261. 20.08.2019.

24. Pratt R.K., Fairbank J.C., Virr A. The reliability of the Shuttle Walking Test, the Swiss Spinal Stenosis Questionnaire, the Oxford Spinal Stenosis Score, and the Oswestry Disability Index in the assessment of patients with lumbar spinal stenosis. Spine 2002; 27(1): 84-91, https://doi.org/10.1097/00007632200201010-00020.

25. Stucki G., Daltroy L., Liang M.H., Lipson S.J., Fossel A.H., Katz J.N. Measurement properties of a selfadministered outcome measure in lumbar spinal stenosis. Spine 1996; 21(7): 796-803, https://doi.org/10.1097/00007632$199604010-00004$.

26. Byval'tsev V.A., Belykh E.G., Sorokovikov V.A., Arsent'eva N.I. The use of scales and questionnaires in vertebrology. Zhurnal nevrologii i psikhiatrii imeni S.S. Korsakova 2011; 111(9 Pt 2): 51-56.

27. Macnab I. Negative disc exploration. An analysis of the causes of nerve-root involvement in sixty-eight patients. $J$ Bone Joint Surg Am 1971; 53(5): 891-903, https://doi. org/10.2106/00004623-197153050-00004.

28. Jansson K.-Å., Blomqvist P., Granath F., Németh G. Spinal stenosis surgery in Sweden 1987-1999. Eur Spine J 2003; 12(5): 535-541, https://doi.org/10.1007/s00586-003-0544-9.

29. Frazier D.D., Lipson S.J., Fossel A.H., Katz J.N. Associations between spinal deformity and outcomes after decompression for spinal stenosis. Spine 1997; 22(17): 20252029, https://doi.org/10.1097/00007632-199709010-00017.

30. Katz J.N., Lipson S.J., Lew R.A., Grobler L.J., Weinstein J.N., Brick G.W., Fossel A.H., Liang M.H. Lumbar laminectomy alone or with instrumented or noninstrumented arthrodesis in degenerative lumbar spinal stenosis: patient selection, costs, and surgical outcomes. Spine 1997; 22(10): 1123-1131, https://doi.org/10.1097/00007632-19970515000012.

31. Martin B.I., Mirza S.K., Comstock B.A., Gray D.T., Kreuter W., Deyo R.A. Are lumbar spine reoperation rates falling with greater use of fusion surgery and new surgical technology? Spine 2007; 32(19): 2119-2126, https://doi. org/10.1097/brs.0b013e318145a56a.

32. Försth P., Michaëlsson K., Sandén B. Does fusion improve the outcome after decompressive surgery for lumbar spinal stenosis? A two-year follow-up study involving 5390 patients. Bone Joint J 2013; 95(7): 960-965, https://doi. org/10.1302/0301-620x.95b7.30776.

33. Ghogawala Z., Benzel E.C., Amin-Hanjani S., Barker F.G. 2nd, Harrington J.F., Magge S.N., Strugar J.,
Coumans J.V., Borges L.F. Prospective outcomes evaluation after decompression with or without instrumented fusion for lumbar stenosis and degenerative Grade I spondylolisthesis. J Neurosurg Spine 2004; 1(3): 267-272, https://doi. org/10.3171/spi.2004.1.3.0267.

34. Herkowitz H.N., Kurz L. Degenerative lumbar spondylolisthesis with spinal stenosis. A prospective study comparing decompression with decompression and intertransverse process arthrodesis. J Bone Joint Surg Am 1991; 73(6): 802-808, https://doi.org/10.2106/00004623199173060-00002.

35. Grob D., Humke T., Dvorak J. Degenerative lumbar spinal stenosis. Decompression with and without arthrodesis. $J$ Bone Joint Surg Am 1995; 77(7): 1036-1041, https://doi. org/10.2106/00004623-199507000-00009.

36. Deyo R.A., Mirza S.K., Martin B.I., Kreuter W., Goodman D.C., Jarvik J.G. Trends, major medical complications, and charges associated with surgery for lumbar spinal stenosis in older adults. JAMA 2010; 303(13): 12591265, https://doi.org/10.1001/jama.2010.338.

37. Deyo R.A. Treatment of lumbar spinal stenosis: a balancing act. Spine J 2010; 10(7): 625-627, https://doi. org/10.1016/j.spinee.2010.05.006.

38. Munting E., Röder C., Sobottke R., Dietrich D., Aghayev E.; Spine Tango Contributors. Patient outcomes after laminotomy, hemilaminectomy, laminectomy and laminectomy with instrumented fusion for spinal canal stenosis: a propensity score-based study from the Spine Tango registry. Eur Spine $J$ 2015; 24(2): 358-368, https://doi.org/10.1007/s00586-0143349-0.

39. Mannion R.J., Guilfoyle M.R., Efendy J., Nowitzke A.M., Laing R.J., Wood M.J. Minimally invasive lumbar decompression: long-term outcome, morbidity, and the learning curve from the first 50 cases. J Spinal Disord Tech 2012; 25(1): 47-51, https://doi.org/10.1097/bsd.0b013e31820baa1e.

40. Krutko A.V., Durny P., Vasilyev A.I., Bulatov A.V. Minimally invasive surgical treatment for adult degenerative lumbar scoliosis. Hirurgia pozvonochnika 2018; 4: 49-56, https://doi.org/10.14531/ss2014.4.49-56.

41. Gushcha A.O., Kolesov S.V., Poltorako E.N., Kolbovskiy D.A., Kaz'min A.I. Surgical treatment of multilevel lumbar vertebral canal stenosis using dynamic stabilization. Multicenter study. Vestnik travmatologii $i$ ortopedii imeni N.N. Priorova 2017; 4: 11-17, https://doi.org/10.32414/08698678-2017-4-11-17.

42. Byvaltsev V.A., Kalinin A.A., Belykh E.G., Sorokovikov V.A., Shepelev V.V. Optimization of segmental lumbar spine instability treatment using minimally invasive spinal fusion technique. Voprosy neirokhirurgii imeni N.N. Burdenko 2015; 79(3): 45, https:Hdoi.org/10.17116/ neiro201579345-54. 